\title{
Cumulative Live Birth Rates in Patients with Polycystic Ovary Syndrome: Comparing Progestin Primed Ovarian Stimulation Protocol and GnRH- Antagonist Protocol
}

Jingjuan Ji ( $\nabla$ jiaoshou75@126.com )

The First Affiliated Hospital of USTC https://orcid.org/0000-0001-6161-7432

Lihua Luo

The First Affiliated Hospital of USTC

Lingli Huang

The First Affiliated Hospital of USTC

Research

Keywords: cumulative live birth rate, progestin primed ovarian stimulation, GNRH antagonist, polycystic ovary syndrome

Posted Date: October 20th, 2020

DOI: https://doi.org/10.21203/rs.3.rs-93402/v1

License: (c) (i) This work is licensed under a Creative Commons Attribution 4.0 International License.

Read Full License 


\section{Abstract}

Background: Cumulative live birth rate (CLBR) becomes a comprehensive and meaningful indictor of the success of IVF nowadays. Frozen-embryo transfer (FET) was associated with a higher rate of live birth and a lower risk of the ovarian hyperstimulation syndrome (OHSS) in polycystic ovary syndrome (PCOS) patients. Progestin-primed ovarian stimulation (PPOS) is a new ovarian stimulation protocol in which oral progestin been used to prevent premature luteinizing hormone (LH) surges during ovarian stimulation. The purpose of the current study is to investigate the CLBR of an in vitro fertilization (IVF) cycle in women with PCOS following PPOS protocol compared with gonadotropin releasing hormone (GnRH) antagonist protocol.

Methods: It is a retrospective study. The first IVF cycle of 666 PCOS women were included. Ovarian stimulations were performed with PPOS or GnRH antagonist protocol. All patients included in the analysis had either delivered a baby or had used all their embryos of their first stimulated cycle. The patients were followed for 2-7 years until February 2020.

Result(s): The CLBR were similar in the PPOS and GnRH antagonist group (64\% vs $60.1 \%, \mathrm{P}=0.748$ ). Logistic regression analyses showed treatment protocol (PPOS vs GnRH antagonist) did not show any significant correlation with the CLBR (adjusted OR: $0.898 ; 95 \% \mathrm{Cl}$ : $0.583-1.384, \mathrm{P}=0.627$ ). No statistically significant differences were found in the live birth rates per embryo transfer $(41.3 \%$ vs. $38.4 \%)$ in the study group and controls.

Conclusion(s): The results of this study showed that both the live birth rate per embryo transfer and the cumulative live birth rate were similar between PPOS and GnRH antagonist group. PPOS protocol is efficient in the controlled ovarian stimulation of patients with PCOS.

\section{Background}

Polycystic ovary syndrome (PCOS) is the most popular endocrine disorder which affects $9-21 \%$ reproductive age women [1-3]. It accounts for about $80 \%$ of women with anovulatory infertility [4].In vitro fertilization (IVF) is a commonly used infertility treatment for PCOS patients who fail to conceive with ovulation induction or if there are concomitant infertility factors such as tubal damage or male subfertility. However, there are many concerns about the efficacy and safety of this procedure. Women with PCOS who require IVF are at high risk of ovarian hyperstimulation syndrome (OHSS), a potentially life-threatening complication [5, 6].Moreover, after achieve pregnancy through IVF, PCOS women are associated with increased risk of maternal and neonatal complications, including gestational diabetes mellitus, pregnancy-induced hypertension, preterm birth, large-for-gestational-age babies, etc[711].Careful strategies are needed to minimize these risks.

Several recent multicenter randomized controlled trial have demonstrated that the "freeze-all" strategy (all the embryos transferable were cryopreserved for later transfer) is not only associated with a higher live birth rate(LBR) but also a lower risk of the OHSS and pregnancy complications in PCOS patients treated 
for IVF $[12,13]$. For this reason as well as the progress of vitrification, protocols used for controlled ovarian stimulation (COS) in PCOS women need not consider whether or not fresh ET can be applied.

GnRH antagonist protocol is now the most commonly used COS protocol in PCOS patients due to the significantly reduced risk of OHSS especially when gonadotropin releasing hormone agonist ( $\mathrm{GnRHa}$ ) was used for trigger [14-16]. However, GnRH antagonist is expensive. Progestin-primed ovarian stimulation (PPOS) is a new stimulation protocol in which oral progestin been used as an alternative to $\mathrm{GnRH}$ analog to prevent premature LH surges during ovarian stimulation. In this protocol, ovulation was co-triggered with GnRH agonist and low dose hCG and "freeze-all" strategy was applied. It has been reported that this protocol yields a similar or even better pregnancy outcome per embryo transfer cycle compared with conventional gonadotropin releasing hormone agonist ( $\mathrm{GnRHa}$ ) short protocol [17-19]. In addition, oral progestin has the advantage of being convenient and cheap.

Traditionally, the success of IVF has been reported as live birth rates of fresh embryo transfer. Cumulative live birth rate (CLBR) is defined as the rate of deliveries resulting from the transfer of all (fresh plus frozen-thawed) embryos from the same stimulation. Nowadays, with the improvements of vitrification, CLBR becomes a comprehensive, relevant and meaningful indictor of the success of IVF [20-22].

The literatures on the use of PPOS protocol in women with PCOS for IVF only investigating the clinical pregnancy rate or ongoing pregnancy rate per transfer, cumulative success rate especially CLBR had not been showed in those studies [18]. Furthermore, their study compared PPOS protocol with GnRH agonist short protocol, which is rarely used in COS of PCOS patients nowadays.

The aim of the present study was to evaluate the effectiveness of PPOS protocol in PCOS women referred for their first ART cycle through comparing the cumulative live birth rate of it with $\mathrm{GnRH}$ antagonist protocol.

\section{Materials And Methods}

\section{Study design}

This was a retrospective analysis including PCOS women who performed their first artificial reproductive technology (ART) cycle with PPOS protocol or GnRH-antagonist protocol in our centre from July 2013 to June 2018. The cycles were followed to February 2020.The objective of this study was to compare cumulative live birth rate of PPOS protocol and GnRH-antagonist protocol. The study was approved by the institutional ethics committee of The First Affiliated Hospital of USTC.

\section{Participants}

PCOS was diagnosed according to Rotterdam consensus as fulfilling at least two of the three criteria: 1) oligo-anovulation or anovulation;2) clinical or biochemical signs of hyperandrogenism; and 3)polycystic ovarian morphology on ultrasound, as defined by at least one ovary with $\otimes 12$ follicles or volume $\otimes 10$ $\mathrm{cm}^{3}[23]$. Exclusion criteria were: other causes of hyperandrogenism and ovulation dysfunction; patients $\rrbracket$ 
20 or $>40$ years of age at oocyte retrieval; history of recurrent miscarriage; congenital uterine malformations; abnormal chromosome karyotype, preimplantation genetic diagnosis (PGD) cycles, no embryo transferable cycles.

\section{Treatment protocols}

\section{GnRH antagonist protocol}

Recombinant FSH (Gonal-f; Merck Serono, Geneva, Switzerland) was started on Days 2-3 of the progesterone induced or spontaneous menstrual cycle and continued until the day of ovulation induction. The initiation doses will be $112.5 \mathrm{lU} /$ day for patients weighing $\leq 60 \mathrm{~kg}$ and $150 \mathrm{lU} /$ day for patients weighing $>60 \mathrm{~kg}$. At day 5-6 of ovarian stimulation, the rFSH doses were adjusted according to ovarian response evaluated by transvaginal ultrasonography and serum hormone tests. GnRH antagonist (Cetrorelix; Merck Serono, Darmstadt, Germany) at a daily dose of $250 \mu \mathrm{g}$ was started when the largest follicle exceeded $12 \mathrm{~mm}$. Recombine human chorionic gonadotropin (r-hCG) 250ug (Ovitrelle; Merck Serono, Geneva, Switzerland) was administered to trigger oocyte maturation when two or more follicles were $\geq 18 \mathrm{~mm}$. If the patients were at highly risk of ovarian hyperstimulation syndrome (OHSS) (over 1618 follicles were $>11 \mathrm{~mm}$ diameter on the day of triggering), ovulation triggering was performed either by administration of triptorelin $0.2 \mathrm{mg}$ (Decapeptyl, Ferring Pharmaceuticals, Netherlands) or by triptorelin 0.2 concomitant with 1000 IU of hCG. In that case, "freeze-all" strategy was applied.

\section{PPOS protocol}

Ovarian stimulation was initiated on menstrual cycle Day 2-3 with daily injection of r-FSH (Gonal-f; Merck Serono, Geneva, Switzerland) combined with oral MPA (6-8 mg/d, Shanghai Xinyi Pharmaceutical Co., China). The initiation doses was $112.5 \mathrm{IU} /$ day for patients weighing $\leq 60 \mathrm{~kg}$ and $150 \mathrm{lU} /$ day for patients weighing $>60 \mathrm{~kg}$ also. After 5 days of stimulation, transvaginal ultrasound scans and serum hormone tests will be performed to adjust FSH doses. When three dominant follicles reached $18 \mathrm{~mm}$ in diameter, the final stage of oocyte maturation was co-triggered by triptorelin $0.2 \mathrm{mg}$ (Decapeptyl, Ferring Pharmaceuticals, Netherlands) and hCG 1000 IU ( Lizhu Pharmaceutical Trading Co., China).

Transvaginal ultrasound-guided oocyte retrieval was performed $34-36 \mathrm{~h}$ after trigging. Collected oocytes were inseminated either via conventional IVF or ICSI. Embryos were examined on Day 3 after insemination. Two good-quality embryos (including grade 1 and grade 2 6-8-cell embryos) were frozen by vitrification on the third day after oocyte retrieval. Surplus embryos were placed in extended culture to day 5 or day 6 . Embryos were graded as 1 (good), 2(reasonable), or 3(moderate) according to the number of cells, degree of fragmentation and renewed development of the embryo. This standard was based on the ESHRE Istanbul consensus on embryo assessment [24]. Only grade 1-3 blastocysts were frozen. The laboratory procedure of vitrification and warming for Day 3 embryos was the same as the method used

for human oocytes reported by Tong et al [25]. For blastocysts, a glass micro-needle was used to collapse the blastocyst before vitrification. The following steps were the same as for the Day 3 embryos.ET was 
performed under ultrasound guidance. Intravaginal progesterone gel (Crinone gel $8 \%$, Serono) was administered for luteal phase support from the day after oocyte retrieval until 8-10 weeks of pregnancy.

In order to ensure validation of complete cycles, this study only involved patients who had already used all their frozen embryos from the present oocyte retrieval or gave live birth to a child.

\section{Fresh embryo transfer}

Fresh ET was intended for the patients triggering with hcg and no signs of early OHSS in GnRH antagonist protocol. OHSS was diagnosis according to the guideline of Practice Committee of the American Society for Reproductive Medicine [26].

\section{Frozen-thawed embryo transfer}

'Freeze-all' strategies were applied in PPOS group. For patients triggering with in triptorelin or at high risk of OHSS in GnRH antagonist group, 'Freeze-all' strategies were also applied. In this study, endometrium preparation method of FET was the same in the two groups. In brief, hormone replacement treatment cycle or letrozole-induced- ovulation cycle was choose based on the discretion of physicians and/or patients' preference. In letrozole -induced- ovulation cycle, letrozole $5 \mathrm{mg}$ was administered for 5 days, and then, follicle growth was monitored beginning on day 10 . If no dominant follicles were found, a low dose of HMG (75 IU/day) was used to stimulate follicle growth and endometrial lining.Day-3 ET was performed 4 days after spontaneous or hCG-induced LH surge while blastocyst transfer was performed 6 days after spontaneous or hCG-induced LH surge. In hormone replacement treatment cycle, estradiol valerate (progynova, Schering, German) was taken $6 \mathrm{mg} / \mathrm{d}$ from menstrual cycle day 2-3. An ultrasound assessment was done 12 to 14 days later to assess endometrium thickness. Progesterone $40 \mathrm{mg} / \mathrm{d} \mathbb{}$ which would be changed to $60 \mathrm{mg} / \mathrm{d} 2$ days later, was given to transform the endometrium, provided the endometrial thickness exceeded $8 \mathrm{~mm}$. Embryo transfer was performed 4 days after progesterone administration for day-3 embryos or 6 days later for blastocysts.

\section{Main outcome measure and statistical analysis}

The primary outcome was the CLBR defined as the delivery rate of a live infant (>24 weeks of gestation) in fresh or subsequent FET cycles in relation to one oocyte retrieved. Only the first delivery was considered in the analysis.

All analyses have been performed using IBM Spss statistics 21. For continuous variables, Student's t-test and Mann-Whitney test were used for data with homogeneous variance and heterogeneous variance respectively. The $\mathrm{x}^{2}$ test was used for categorical variables. Logistic regression analyses were conducted to identify independent correlates between each possible confounding factor, especially treatment protocol and cumulative LBR after adjusting for other confounders that were identified in our univariate analysis. $\mathrm{P}<.05$ was considered statistically significant. 


\section{Results}

\section{Patient characteristics}

Of the total of 666 women who were assessed for eligibility, 328 cases were involved in the study group (PPOS group) and 338 to the control group (GnRH antagonist group). Baseline characteristics of the patients in this study are shown in Table I. Age, BMI, basal sex hormone (FSH, LH, E2, T) value and duration of infertility were comparable between the two groups. Also, there was no significant difference in indications for ART between the two groups. In the study, 40/328ه12.2\%囚of the study group and $37 / 338(10.9 \%)$ of the control group had previously delivery $(p=0.755)$.

\section{Ovarian Stimulation, Follicle Development, Oocyte Performance}

Table II describes the ovarian stimulation characteristics and embryological outcomes of ovarian stimulation treatment in both groups.

The total gonadotropin $₫ \mathrm{Gn} \llbracket$ dose was comparable between PPOS group and $\mathrm{GnRH}$ antagonist protocol (2209.5 \pm 1372.5 versus $2170.5 \pm 1155 I U, P=0.426)$. There was no statistical difference in mean

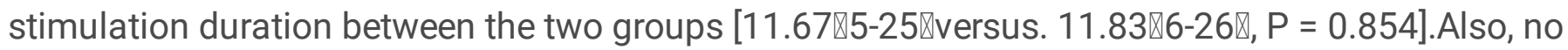
significantly difference was found in oocyte number between PPOS group and GnRH antagonist group [14.83 (2-50) versus. 15.08(2-46), $\mathrm{P}>0$.05].The mean number of high-quality cleaved embryos was $6.38(0-20)$ in the PPOS group and 5.79(0-32) in the GnRH antagonist group $(P=0.462)$.

Similarly, there was no significant difference in cryopreserved day 5/6 embryos between the two groups $(P>0.05)$. There was only 1 patient in PPOS group experienced moderate OHSS during the study, while in GnRH antagonist group there were 12 patients suffered early OHSS and 3 patients suffered later OHSS(P区 $0.000)$.

\section{Embryo characteristics and reproductive outcome}

Embryo characteristics and reproductive outcome are listed in Table III. The proportion of blastocysts transfer was similar between the study group and the GnRH antagonist group (42.6\%vs. $37.1 \%$, $\mathrm{p}=0.186$ ).Also, the proportion of double embryo transfer was similar between the study group and the GnRH antagonist group (60.7\%vs. 61.1\%,p=0.934). The number of blastocysts transferred [1.27(1-2)vs. 1.36(1-2)] and number of day-3 embryos transferred in FET cycles [1.95(1-2)vs. 1.99(1-2)] showed no significant difference between the two groups $(P>0.05)$. The live birth rate per transfer was 210/509 $(41.3 \%)$ in the study group, while the live birth rate per transfer in the $\mathrm{GnRH}$ antagonist group was $203 / 529(38.4 \%)$.No significantly difference was found in the cumulative pregnancy rate between the two groups (210/328 (64\%) vs. 203/338 (60.1\%); P>0.05).

\section{Prognostic covariate analyses}


In the Logistic regression analyses model for both the PPOS and antagonist groups, age had a significant influence on the CLBR (adjusted OR: 0.918; $95 \% \mathrm{Cl}: 0.867-0.973 ; \mathrm{P}=0.004$ ). BMI and duration of infertility did not show any significance in the model, adjusted OR being $(0.981 ; 95 \% \mathrm{Cl}: 0.929-1.035)$ and $(0.974$; 95\% Cl: 0.881-1.076).

The number of retrieved oocytes, as a continuous variable, show significant correlation with the CLBR (adjusted OR: 1.037; 95\% Cl: 1.010-1.065). Treatment protocol (PPOS or GnRH antagonist) did not show any significant correlation with the CLBR (adjusted OR: 0.898; 95\% Cl: 0.583-1.384, $\mathrm{P}=0.627$ ).

\section{Discussion}

The results of the study provided first-time evidence that, compared with GnRH antagonist protocol, PPOS protocol resulted in a similar cumulative live birth rate among patients with PCOS.PPOS protocol is effective for COS in PCOS women undergoing IVF. Our study indicated that the embryos originating from this regimen had similar developmental potential as those from the $\mathrm{GnRH}$ antagonist protocol. These results will help establish a new regimen for ovarian stimulation in women with PCOS.

In the study of Kuang et al, it was found that the duration and dose of gonadotropin in PPOS protocol were higher than GnRH short protocol [17]. Another study by Wang et al showed that the duration of gonadotropin administration was similar between PPOS protocol (MPA10 mg and hMG) and GnRH agonist short protocol, but gonadotropin dose was significantly higher in PPOS protocol [18].Different from their study, we found that both the duration of stimulation and the Gn dose were comparable between PPOS group and GnRH antagonist protocol. A potential explanation for this discrepancy is the fact that in this two previous study, a dose of $10 \mathrm{mg}$ MPA was choose for hypothalamic-pituitary-ovarian (HPO) axis suppression during ovarian stimulation which may lead to stronger pituitary suppression [27, 28]. In our study, we decrease the MPA dose to 6-8 mg and found that 6-8 mg MPA is efficient for preventing premature LH surge in PCOS women. This dose may alleviate pituitary suppression and decrease $\mathrm{Gn}$ dose at the same time. Further research is needed to explore the optimal dose of MPA.

Kuang et al compared PPOS protocol with GnRH agonist short protocol and showed that the rates of oocyte retrieval, mature oocytes, fertilization, and cleaved embryos were similar between the two groups. The FET results also proved that the embryos from the PPOS protocol had similar developmental potential compared with GnRH agonist short protocol [17]. Wang et al reported the comparable pregnancy outcome of PPOS protocol compared with GnRH agonist short protocol in PCOS patients [18]. The study of Zhu et al suggested that PPOS protocol using Utrogestan to block the LH surge showed a better clinical outcome compared with GnRH agonist short protocol [19]. Our study showed that the oocyte retrieved, high-quality cleaved embryos, blastocyst formation rate and cumulative live birth rate were comparable between the PPOS group and the GnRH antagonist group. The results support that PPOS protocol is effective and feasible in COS for PCOS patients during their IVF treatment.

Previous study of high responders demonstrated that transfer of frozen-thaw embryos associated with comparable or better reproductive outcomes and low risk of OHSS than fresh embryo [13, 29-32]. These 
previous studies reported only reproductive outcomes per first transfer for women in the 'freeze-all' group compared with those in the 'fresh-transfer' group. Evaluate IVF success rates based on per embryo transfer alone is incomplete and inappropriate [33]. Cumulative live birth rate per oocyte retrieval summarizes the chance of live birth during an entire treatment period [21, 33]. To date, there have been only a limited number of randomized controlled studies (RCTs) compared cumulative live birth rate of 'freeze-all' versus 'fresh-transfer' strategy [34].The result of Li et al demonstrated that the cumulative live birth rate of 'freeze-all' strategy is similar as the 'fresh-transfer' strategy among high responders [35]. None of previous study has compared the cumulative live birth rate of high responders between different treatment protocols. This is to our knowledge, the first study comparing CLBR between PPOS and GnRH antagonist protocols. We included women with PCOS referred for their first IVF cycle within the age range of 20-39 years. As PCOS is highly prevalent $[2,36]$ in infertility patients, these results may be benefit for a large proportion of patients seeking IVF treatment. The result of this study showed that the CLBRs were comparable between PPOS group and GnRH antagonist group, with $64 \%$ and $60.1 \%$ achieving at least one live birth respectively. The result of our study demonstrated that PPOS protocol is as effective as GnRH antagonist protocol for COS in women with PCOS.

Ovarian hyperstimulation syndrome (OHSS) is a severe iatrogenic complication of ovulation induction during assisted reproduction. Occurrence of OHSS depends upon hCG, either following hcg trigger during COS (Early OHSS) or an endogenous increase from the initiated pregnancy (Late OHSS) [37, 38]. Women with PCOS have a priori risk for development of OHSS. Many efforts have been made to prevent the occurrence of OHSS. Among them, the 'freeze-all' strategy and GnRH agonist trigger is the two most important methods $[39,40]$. Using PPOS protocol, these two methods can be combined the same as GnRH antagonist protocol [17].In our study, low dose of hCG (1000 IU) was used combined with GnRHa to triggering ovulation in PPOS group. The result demonstrated that the risk of moderate or severe OHSS was not increased (only 1 early moderate OHSS occurred).

In line with the results from the between-group analysis, the multivariable regression analysis for CLBR showed that the only significant predictors were the number of oocytes retrieved and the age, whereas $\mathrm{BMI}$ and treatment protocol were not significantly associated.

Cost-effectiveness is a main concern for infertility patients seeking treatment. Instead of GnRH antagonist, MPA is used for down-regulation in PPOS protocol.MPA is much cheaper than GnRH antagonist agents. As the result of our study showed that the $\mathrm{G}$ n dose were comparable between PPOS and $\mathrm{GnRH}$ antagonist protocol, the PPOS protocol is cost-effective owing to the less costly of MPA compared to $\mathrm{GnRH}$ antagonist. Evans et al. assessing the cost-effectiveness of ovulation suppression with progestins compared with GnRH analogues in IVF cycles, progestins were found to be cost-effective compared with GnRH antagonist in "freeze-all" cycles [41]. The result of our study is in line with this study.

We recognize there are some limitations in our study. The retrospective nature of this analysis may be subject to selection bias regarding the type of COS protocol (PPOS vs. GnRH antagonist). In this regard, 
we only involved women undergoing their first IVF/ICSI cycles and meticulously screened patients with the use of strict criteria. Moreover, the baseline characteristics of the two groups were comparable. The sample size of our study need be enlarged. Future RCTS on this subject are needed to look into the details on the effect of PPOS protocol on the COS of PCOS patients.

\section{Conclusion}

The results of this study showed that both the live birth rate per embryo transfer and the cumulative live birth rate were similar between PPOS and GnRH antagonist group. PPOS protocol is efficient in the controlled ovarian stimulation of patients with PCOS treated for IVF.

\section{Abbreviations}

CLBR囚cumulative live birth rate;FET $\bigotimes$ frozen-embryo transfer; OHSS囚ovarian hyperstimulation syndrome; PPOS『progestin-primed ovarian stimulation; LH区luteinizing hormone; IVF: in vitro fertilization; GnRH区 gonadotropin releasing hormone; COS\controlled ovarian stimulation; GnRHa: gonadotropin releasing hormone agonist; ART区artificial reproductive technology; PGD preimplantation genetic diagnosis; rFSH

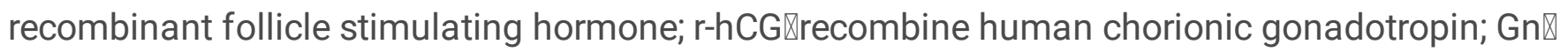
gonadotropin;HPO hypothalamic-pituitary-ovarian

\section{Declarations}

\section{Ethics approval and consent to participate}

The Ethics Committee of The First Affiliated Hospital of USTC approved this study protocol, and informed consent was waived from each individual.

\section{Consent for publication}

Not applicable.

\section{Availability of data and materials}

All data generated or analyzed during this study are included in this published article.

\section{Conflicts of interests}

None declared.

\section{Funding}

No external funding was used.

\section{Authors' contributions}


J.J. was involved in substantial contributions to conception and design, acquisition, analysis and interpretation of data, drafting and revising the article and final approval of the version to be published; L.H. was involved in contributions to analysis and interpretation of data and final approval of the version to be published; L.L. was involved in contributions to acquisition of data and final approval of the version to be published.

\section{Acknowledgements}

We thank the entire staff of the Department of Reproductive Medicine Center, the First Affiliated Hospital of USTC for their support in this study.

\section{References}

1. March WA, Moore VM, Willson KJ, Phillips DI, Norman RJ, Davies MJ. The prevalence of polycystic ovary syndrome in a community sample assessed under contrasting diagnostic criteria. Hum Reprod 2010;25:544-51.

2. Yildiz BO, Bozdag G, Yapici Z, Esinler I, Yarali H. Prevalence, phenotype and cardiometabolic risk of polycystic ovary syndrome under different diagnostic criteria. Hum Reprod 2012;27:3067-73.

3. Lizneva D, Suturina L, Walker W, Brakta S, Gavrilova-Jordan L, Azziz R. Criteria, prevalence, and phenotypes of polycystic ovary syndrome. Fertil Steril 2016;106:6-15.

4. ESHRE/ASRM. Thessaloniki Sponsored PCOS Consensus Workshop Group Consensus on infertility treatment related to polycystic ovary syndrome. Hum Reprod 2008;23:462-77.

5. Delvigne A, Rozenberg S. Epidemiology and prevention of ovarian hyperstimulation syndrome (OHSS): a review. Hum Reprod Update 2002; 8: 559-77.

6. Tang T, Glanville J, Hayden CJ, White D, Barth JH, Balen AH. Combined lifestyle modification and metformin in obese patients with polycystic ovary syndrome: a randomized, placebo-controlled, doubleblind multicentre study. Hum Reprod 2006; 21: 80-9.

7. Hansen M, Kurinczuk JJ, Bower C, Webb S. The risk of major birth defects after intracytoplasmic sperm injection and in vitro fertilization. N Engl J Med 2002; 346: 725-30.

8. Helmerhorst FM, Perquin DA, Donker D, Keirse MJ. Perinatal outcome of singletons and twins after assisted conception: a systematic review of controlled studies. BMJ 2004; 328: 261.

9. Jackson RA, Gibson KA, Wu YW, Croughan MS. Perinatal outcomes in singletons following in vitro fertilization: a meta-analysis. Obstet Gynecol 2004; 103:551-63.

10. Pandey S, Shetty A, Hamilton M, Bhattacharya S, Maheshwari A. Obstetric and perinatal outcomes in singleton pregnancies resulting from IVF/ICSI: a systematic review and meta-analysis. Hum Reprod Update. 2012;18:485-503.

11. Sha T, Wang X, Cheng W, Yan Y.A meta-analysis of pregnancy-related outcomes and complications in women with polycystic ovary syndrome undergoing IVF. Reprod Biomed Online. 2019;39:281-93. 
12. Shi Y, Wei D, Liang X, Sun Y, Liu J, Cao Y, Zhang B, Legro RS, Zhang H, Chen ZJ. Live birth after fresh embryo transfer vs elective embryo cryopreservation/frozen embryo transfer in women with polycystic ovary syndrome undergoing IVF (FreFro-PCOS): study protocol for a multicenter, prospective, randomized controlled clinical trial. Trials 2014;15:154.

13. Chen ZJ, Shi Y, Sun Y, Zhang B, Liang X, Cao Y, Yang J, Liu J, Wei D, Weng N et al. Fresh versus frozen embryos for infertility in the polycystic ovary syndrome. N Engl J Med 2016;375:523-33.

14. Griesinger G, Diedrich K, Tarlatzis BC, Kolibianakis EM. GnRH-antagonists in ovarian stimulation for IVF in patients with poor response to gonadotrophins, polycystic ovary syndrome, and risk of ovarian hyperstimulation: a meta-analysis. Reprod Biomed Online 2006;13:628-38.

15. Lainas TG, Petsas GK, Zorzovilis IZ, Iliadis GS, Lainas GT, Cazlaris HE, Kolibianakis EM. Initiation of $\mathrm{GnRH}$ antagonist on Day 1 of stimulation as compared to the long agonist protocol in PCOS patients. A randomized controlled trial: effect on hormonal levels and follicular development. Hum Reprod 2007;22:1540-6.

16. Lainas TG, Sfontouris IA, Zorzovilis IZ, Petsas GK, Lainas GT, Alexopoulou E, Kolibianakis EM. Flexible $\mathrm{GnRH}$ antagonist protocol versus $\mathrm{GnRH}$ agonist long protocol in patients with polycystic ovary syndrome treated for IVF: a prospective randomized controlled trial (RCT). Hum Reprod 2010;25:683-9.

17. Kuang Y, Chen Q, Fu Y, Wang Y, Hong Q, Lyu Q, Ai A, Shoham Z. Medroxyprogesterone acetate is an effective oral alternative for preventing premature luteinizing hormone surges in women undergoing controlled ovarian hyperstimulation for in vitro fertilization. Fertil Steril. 2015;104:62-70.

18. Wang Y, Chen Q, Wang N, Chen H, Lyu Q, Kuang Y. Controlled Ovarian Stimulation Using Medroxyprogesterone Acetate and hMG in Patients With Polycystic Ovary Syndrome Treated for IVF: A Double-Blind Randomized Crossover Clinical Trial. Medicine (Baltimore). 2016 Mar;95(9):e2939.

19. Zhu XX, Ye HJ, Fu YL. The Utrogestan and hMG protocol in patients with polycystic ovarian syndrome undergoing controlled ovarian hyperstimulation during IVF/ICSI treatments. Medicine. 2016;95:e4193.

20. Germond M, Urner F, Chanson A, Primi MP, Wirthner D, Senn A. What is the most relevant standard of success in assisted reproduction?: The cumulated singleton/twin delivery rates per oocyte pick-up: the CUSIDERA and CUTWIDERA. Hum Reprod 2004;19:2442-4.

21. Malizia BA, Hacker MR, Penzias AS. Cumulative live-birth rates after in vitro fertilization. $N$ Engl J Med 2009;360:236-43.

22. Malizia BA, Dodge LE, Penzias AS, Hacker MR. The cumulative probability of live born multiples after in vitro fertilization: a cohort study of more than 10,000 women. Fertil Steril 2013;99:393-9.

23. Rotterdam ESHRE/ASRM-Sponsored PCOS Consensus Workshop Group. Revised 2003 consensus on diagnostic criteria and long-term health risks related to polycystic ovary syndrome (PCOS). Hum Reprod 2004;19:41-7.

24. Alpha Scientists in Reproductive Medicine and ESHRE Special Interest Group of Embryology. The Istanbul consensus workshop on embryo assessment: proceedings of an expert meeting. Hum 
Reprod 2011;26:1270-83.

25. Tong XH, Wu LM, Jin RT, Luo LH, Luan HB, Liu YS. Fertilization rates are improved after IVF if the corona radiata is left intact in vitrified-warmed human oocytes. Hum Reprod 2012;27:3208-3214.

26. Practice Committee of the American Society for Reproductive Medicine. Electronic address: ASRM@asrm.org1; Practice Committee of the American Society for Reproductive Medicine. Prevention and treatment of moderate and severe ovarian hyperstimulation syndrome: a guideline. Fertil Steril.2016; 106:1634-47.

27. Dong J, Wang Y, Chai WR, Hong QQ, Wang NL, Sun LH, Long H, Wang L, Tian H, Lyu QF, Lu XF, Chen QJ, Kuang YP. The pregnancy outcome of progestin-primed ovarian stimulation using 4 versus $10 \mathrm{mg}$ of medroxyprogesterone acetate per day in infertile women undergoing in vitro fertilization: a randomized controlled trial. BJOG. 2017;124:1048-55.

28. Yu S, Long H, Chang HY, Liu Y, Gao H, Zhu J, Quan X, Lyu Q, Kuang Y, Ai A. New application of dydrogesterone as a part of a progestin-primed ovarian stimulation protocol for IVF: a randomized controlled trial including 516 first IVF/ICSI cycles. Hum Reprod. 2018;33:229-37.

29. Ferraretti AP, Gianaroli L, Magli C, Fortini D, Selman HA, Feliciani E. Elective cryopreservation of all pronucleate embryos in women at risk of ovarian hyperstimulation syndrome: efficiency and safety. Hum Reprod 1999;14:1457-60.

30. Shapiro BS, Daneshmand ST, Garner FC, Aguirre M, Hudson C, Thomas S. Evidence of impaired endometrial receptivity after ovarian stimulation for in vitro fertilization: a prospective randomized trial comparing fresh and frozen-thawed embryo transfers in high responders. Fertil Steril 2011;96:516-518.

31. Aflatoonian A, Mansoori-Torshizi M, Farid Mojtahedi M, Aflatoonian B,Khalili MA, Amir-Arjmand MH, Soleimani M, Aflatoonian N, Oskouian $\mathrm{H}$,Tabibnejad $\mathrm{N}$ et al. Fresh versus frozen embryo transfer after gonadotropin-releasing hormone agonist trigger in gonadotropin-releasing hormone antagonist cycles among high responder women: a randomized, multi-center study. Int J Reprod Biomed (Yazd) 2018;16:9-18.

32. Evans J, Hannan NJ, Edgell TA, Vollenhoven BJ, Lutjen PJ, Osianlis T, Salamonsen LA, Rombauts LJ. Fresh versus frozen embryo transfer: backing clinical decisions with scientific and clinical evidence. Hum Reprod Update 2014;20:808-21.

33. Maheshwari A, McLernon D, Bhattacharya S. Cumulative live birth rate: time for a consensus? Hum Reprod. 2015;30:2703-7.

34. Wong KM, van Wely M, Mol F, Repping S, Mastenbroek S. Fresh versus frozen embryo transfers in assisted reproduction. Cochrane Database Syst Rev 2017;3:CD011184.

35. Li Z, Wang AY, Bowman M, Hammarberg K, Farquhar C, Johnson L, Safi N, Sullivan EA. Cumulative live birth rates following a 'freeze-all' strategy: a population-based study. Hum Reprod Open. 2019 Mar 5; 2019(2):hoz004

36. Azziz R, Woods KS, Reyna R, Key TJ, Knochenhauer ES, Yildiz BO. The prevalence and features of the polycystic ovary syndrome in an unselected population. J Clin Endocrinol Metab 2004;89:2745-9. 
37. Mathur RS, Akande AV, Keay SD, Hunt LP, Jenkins JM. Distinction between early and late ovarian hyperstimulation syndrome. Fertil Steril 2000; 73:901-7.

38. Papanikolaou EG, Pozzobon C, Kolibianakis EM, Camus M, Tournaye H, Fatemi HM, Van Steirteghem A, Devroey P. Incidence and prediction of ovarian hyperstimulation syndrome in women undergoing gonadotropinreleasing hormone antagonist in vitro fertilization cycles. Fertil Steril 2006; 85:112-20.

39. Devroey P, Polyzos NP, Blockeel C. An OHSS-free clinic by segmentation of IVF treatment. Hum Reprod 2011;26:2593-7.

40. Roque M, Haahr T, Geber S, Esteves SC, Humaidan P. Fresh versus elective frozen embryo transfer in IVF/ICSI cycles: a systematic review and meta-analysis of reproductive outcomes. Hum Reprod Update. 2019;25:2-14.

41. Evans MB, Parikh T, DeCherney AH, Csokmay JM, Healy MW, Hill MJ. Evaluation of the costeffectiveness of ovulation suppression with progestins compared with $\mathrm{GnRH}$ analogs in assisted reproduction cycles. Reprod Biomed Online. 2019;38:691-8.

\section{Tables}


Table I

Baseline characteristics on menstrual cycle Days 1-3 in women treated with either PPOS or GnRH antagonist.

\begin{tabular}{|c|c|c|c|}
\hline & PPOS group(n = 328 ) & Antagonist group( $n=338$ ) & $\mathbf{P}$ \\
\hline Age at inclusion (year) & $29.3(21-39)$ & $28.64(20-39)$ & $0.064^{\mathrm{a}}$ \\
\hline BMI (kg/m2), & $23.25(16.8-32.5)$ & $23.47(16.41-33.87)$ & $0.756^{a}$ \\
\hline Duration of infertility (years), & $3.36(1-16)$ & $3.11(1-10)$ & $0.733^{a}$ \\
\hline Previous pregnancy, \% (n) & $130 / 328(39.69 \%)$ & $126 / 338(37.3 \%)$ & $0.677^{b}$ \\
\hline Previous delivery, $\mathrm{n}(\%)$ & $40 / 328(12.2 \%)$ & $37 / 338(10.9 \%)$ & $0.755^{b}$ \\
\hline Indication for IVF n (\%) & & & $0.372^{b}$ \\
\hline PCOS only & $80 / 328(24.4 \%)$ & 93/338 (27.5\%) & \\
\hline PCOS + male factor & $62 / 328(18.9 \%)$ & $76 / 338(22.5 \%)$ & \\
\hline PCOS + tubal factor & $173 / 328(52.7 \%)$ & 139/338 (41.0\%) & \\
\hline PCOS + other & $13 / 328(4.0 \%)$ & $30 / 338(8.88 \%)$ & \\
\hline bFSH (IU/L) & $4.48 \pm 3.26$ & $4.81 \pm 3.34$ & $0.598^{c}$ \\
\hline $\mathrm{bLH}(\mathrm{IU} / \mathrm{L})$ & $3.84 \pm 4.26$ & $4.39 \pm 4.11$ & $0.32^{c}$ \\
\hline bE2 (pg/mL) & $31.67 \pm 28.34$ & $30.86 \pm 24.52$ & $0.859^{c}$ \\
\hline $\mathrm{T}$ & $0.3820 \pm 0.368$ & $0.364 \pm 0.285$ & $0.736^{c}$ \\
\hline
\end{tabular}


Table II

Treatment characteristics in women allocated to either PPOS or GnRH-antagonist protocol.

\begin{tabular}{|c|c|c|c|}
\hline & $\begin{array}{l}\text { PPOS group }(n= \\
328)\end{array}$ & $\begin{array}{l}\text { GnRH antagonist group }(\mathrm{n}= \\
\text { 338) }\end{array}$ & $\begin{array}{l}\text { P- } \\
\text { value }\end{array}$ \\
\hline Days of stimulation(day) & $11.67(5-25)$ & $11.83(6-26)$ & $\begin{array}{l}0.854 \\
\mathrm{a}\end{array}$ \\
\hline Total dose of Gonadotrophins(IU) & $2209.5 \pm 1372.5$ & $2170.6 \pm 1155$ & $\begin{array}{l}0.426 \\
b\end{array}$ \\
\hline Oocyte retrieve(n) & $14.83(2-50)$ & $15.08(2-46)$ & $\begin{array}{l}0.729 \\
\mathrm{a}\end{array}$ \\
\hline Fertilized oocytes (n) & $10.21(1-47)$ & $9.82(1-38)$ & $\begin{array}{l}0.386 \\
\mathrm{a}\end{array}$ \\
\hline high-quality Cleaved embryos (n) & $6.38(0-20)$ & $5.79(0-32)$ & $\begin{array}{l}0.462 \\
\mathrm{a}\end{array}$ \\
\hline $\begin{array}{l}\text { Cryopreserved day } 5 / 6 \text { embryos } \\
\text { (n) }\end{array}$ & $3.45(0-12)$ & $3.04(0-16)$ & $0.36^{a}$ \\
\hline $\begin{array}{l}\text { Early moderate/severe OHSS n/n } \\
(\%)\end{array}$ & $1 / 328(0.30 \%)$ & $12 / 338(2.67 \%)$ & $\begin{array}{l}0.000 \\
c\end{array}$ \\
\hline $\begin{array}{l}\text { Late moderate/severe OHSS } \mathrm{n} / \mathrm{n} \\
(\%)\end{array}$ & 0 & $3 / 338(0.89 \%)$ & $\begin{array}{l}0.000 \\
c\end{array}$ \\
\hline
\end{tabular}


Table III

Embryo characteristics and reproductive outcome in women treated either with PPOS or GnRH-antagonist protocol.

\begin{tabular}{|c|c|c|c|}
\hline & $\begin{array}{l}\text { PPOS group }(n= \\
328)\end{array}$ & $\begin{array}{l}\text { GnRH antagonist group ( } \mathrm{n} \\
=338 \text { ) }\end{array}$ & $\begin{array}{l}\mathrm{P}- \\
\text { value }\end{array}$ \\
\hline Blastocyst transfer, n/n (\%) & 217/509 (42.6\%) & 196/529 (37.1\%) & $\begin{array}{l}0.186 \\
c\end{array}$ \\
\hline Day-3 embryo transfer, n/n (\%) & $292 / 509$ (57.4\%) & $333 / 529(62.9 \%)$ & \\
\hline $\begin{array}{l}\text { number of blastocysts transferred in FET } \\
\text { cycles }\end{array}$ & $1.27(1-2)$ & $1.36(1-2)$ & $\begin{array}{l}0.180 \\
\mathrm{a}\end{array}$ \\
\hline $\begin{array}{l}\text { number of Day-3 embryos transferred in } \\
\text { FET cycles }\end{array}$ & $1.95(1-2)$ & $1.99(1-2)$ & $\begin{array}{l}0.106 \\
a\end{array}$ \\
\hline Double embryo transfer $\mathrm{n} / \mathrm{n}(\%)$ & $309 / 509(60.7 \%)$ & $323 / 529(61.1 \%)$ & $\begin{array}{l}0.934 \\
\mathrm{c}\end{array}$ \\
\hline Single embryo transfer $\mathrm{n} / \mathrm{n}(\%)$ & 200/509 (39.3\%) & $206 / 529(38.9 \%)$ & \\
\hline Live birth rate per ET & $210 / 509(41.3 \%)$ & $203 / 529(38.4 \%)$ & $\begin{array}{l}0.508 \\
a\end{array}$ \\
\hline Cumulative live birth, n (\%) & $210 / 328(64 \%)$ & $203 / 338(60.1 \%)$ & $\begin{array}{l}0.748 \\
a\end{array}$ \\
\hline $\begin{array}{l}\text { a Pearson } \times 2 \text { test. Values are number (pe } \\
\text { median (minimum-maximum) }\end{array}$ & ge) b Two-san & Mann-Whitney test. Val & \\
\hline
\end{tabular}


Table $₫$

Multivariable analysis of variables for cumulative live birth rate

\begin{tabular}{|lllll|}
\hline & Unadjusted ORs & P-value & Adjusted ORs (95\% Cl) & P-value \\
\hline Age (year) & $0.906(0.859-0.956)$ & 0.000 & $0.918(0.867-0.973)$ & $0.004^{\mathrm{a}}$ \\
\hline Duration of infertility (year) & $0.921(0.841-1.009)$ & 0.077 & $0.974(0.881-1.076))$ & $0.606^{\mathrm{a}}$ \\
\hline No. of oocytes & $1.043(1.016-1.071)$ & 0.001 & $1.037(1.010-1.065)$ & $0.007^{\mathrm{a}}$ \\
\hline BMI & $0.959(0.912-1.009)$ & 0.104 & $0.981(0.929-1.035)$ & $0.478^{\mathrm{a}}$ \\
\hline Treatment protocol & & & & \\
\hline PPoS & $0.944(0.621-1.453)$ & 0.787 & $0.898(0.583-1.384)$ & $0.627^{\mathrm{b}}$ \\
\hline Antagonist group & Reference & & Reference & \\
\hline $\begin{array}{l}\text { a P-value of each variable's overall effects after adjusting for the other variables. b P-value between } \\
\text { each variable's subgroups and reference group. }\end{array}$ & & \\
\hline
\end{tabular}

